\title{
CIDADANIA E INCLUSÃO: DESAFIOS PARA A FORMAÇÃO DOCENTE
}

\author{
Hiata Anderson Nascimento \\ Instituto Federal do Espírito Santo \\ hiata.nascimento@ifes.edu.br
}

\section{Resumo}

Trata-se de uma reflexão acerca dos desafios colocados pela educação inclusiva à formação docente. A análise resultou de um curso de formação continuada realizado no Instituto Federal do Espírito Santo, com 15 professores/as da rede municipal da cidade de Barra de São Francisco/ES, no ano de 2015. A intenção era oferecer aos docentes do ensino fundamental, ferramentas conceituais que os habilitassem a elaborar projetos de educação inclusiva em seus espaços de trabalho, bem como fomentar um olhar 'desnaturalizador' acerca dos processos de exclusão social. Ao final do curso ficou evidenciada necessidade de se investir em percursos formativos que salientem a centralidade da empatia como o afeto que pavimenta o reconhecimento da humanidade dos que se encontram fora dos padrões de normalidade.

Palavras-chave: Educação Inclusiva. Cidadania. Diferença. Diversidade. Empatia.

\section{CITIZENSHIP AND INCLUSION: CHALLENGES TO PREPARE TEACHERS}

\section{Abstract}

It is about the reflection of the challenges imposed by the inclusive education to prepare teachers. The analysis resulted from a continuing education program offered at the Federal Institute of Espirito Santo, with participation of 15 teachers from the public education school system in the town of Barra de Sao Francisco/ ES, in 2015. The intention was to offer conceptual tools to the teachers of the primary school to allow them to elaborate projects of inclusive education in their workplaces as well as to foment a denaturant look of the processes of social exclusion. At the end of the course it was evident the necessity of investing in pre courses that stress the centrality of empathy as the affection that paves the acknowledgement of the humanity of those who are not within the standards of normality.

Keywords: Inclusive Education. Citizenship. Difference. Diversity. Empathy.

\section{CIUDADANÍA E INCLUSIÓN: DESAFIOS PARA LA FORMACIÓN DOCENTE}

\section{Resumen}

Se trata de una reflexión sobre los desafios de la formación de maestros de educación inclusiva . El análisis dio lugar a un curso de educación continua realizada en el Instituto Federal del Espírito Santo, con 15 profesores de la ciudad de San Francisco, en 2015. La intención era ofrecer a los maestros de la escuela primaria, herramientas conceptuales que habilitassem para desarrollar proyectos de educación inclusiva en sus áreas de trabajo, así como el fomento de una mirada "desnaturalizante " sobre los procesos de exclusión social. Al final del curso se hizo evidente la necesidad de invertir en el aprendizaje que hacen hincapié en la importancia de la empatía como el afecto que pavimenta el reconocimiento de la humanidad de los que están fuera del rango normal.

Palavras clave: Educación Inclusiva. Ciudadanía. Diferencia. Diversidad. Empatía. 
Cidadania e inclusão: desafios para a formação docente

\section{INTRODUÇÃO}

Este trabalho tem o objetivo de apresentar uma reflexão sobre os desafios colocados pela educação inclusiva à formação docente. A partir de um relato de experiência, pretende-se problematizar as dimensões éticas e políticas presentes no fazer pedagógico, sobretudo, nas vivências e nas experiências de encontro com o outro, desencadeadas no espaço da sala de aula. Ademais, dá-se destaque para a importância do/a professor/a nesse processo - aqui apreendido/a como agente possibilitador/a da emancipação ou, pelo contrário, da manutenção de sistemas, práticas e mecanismos de exclusão.

No contexto das sociedades contemporâneas, marcadas por intensas mudanças sociais, três palavras emergem com um certo destaque: diversidade, pluralidade e diferença. Estamos diante de palavras que têm se tornado cada vez mais presentes nos discursos sociais. Passando pela fala de professores/as inseridos/as em suas realidades da sala de aula e terminando na produção/elaboração de políticas públicas, tais expressões apontam para o surgimento de um novo paradigma social, voltado para a valorização da diferença e das diversidades. Nesse contexto, encontramos discursos que ressaltam a valoração positiva da diversidade, enquanto que por outro lado, observamos discursos fortes, que tomam tais processos de transformação social como signos da degradação moral da sociedade. Nesse cenário de intensos confrontos morais, a escola aparece como a arena na qual esses embates têm se configurado de maneira mais visível. (CARRARA et al, 2011).

Silva (2013) destaca que por muito tempo, a escola não foi o lugar para a diferença. Por muito tempo, o ambiente da escola mostrou-se hostil aos seres humanos que não se encaixavam dentro de uma determinada expectativa social, o que fazia com que essas pessoas fossem condenadas ao silêncio e à invisibilidade.

Desde o final da Segunda Guerra, diversos movimentos foram feitos no sentido de se repensar e reposicionar a sociedade em geral e a escola em particular, no que diz respeito às pessoas com necessidades específicas. No longo caminho rumo à construção de uma sociedade mais justa, a educação entrou em cena como uma das mais importantes vias para a cidadania e para a ascensão social de um contingente cada vez maior de pessoas. Passamos a crer que "não há inclusão sem cidadania e nem cidadania sem inclusão" e que a pluralidade, mesmo 'incômoda', deveria ser reconhecida e aceita, por tratar-se de uma das facetas mais marcantes da 'condição humana'. (ARENDT, 2010). 
Cidadania e inclusão: desafios para a formação docente

A proposta de uma sociedade e de uma escola inclusivas, firma-se como utópica, mas por isso mesmo, impregnada de elementos transformadores. A dimensão utópica presente nas falas e nas propostas de construção de uma escola para todos/as, permite que pensemos o que antes era tido como impensável e que desarticulemos crenças e valores até então considerados inabaláveis e inquestionáveis, posto sustentarem todas as práticas que impediam o acesso de algumas/mas aos benefícios sociais.

Entra em cena o questionamento dos valores que fundamentam as práticas pedagógicas. Aqui se faz necessário questionar o modo como o currículo é desenhado e posto em prática em sala de aula. Indicamos que ele é espaço de luta e de enfrentamentos políticos. Nele, temas são explicitados, trazidos à cena pública. Nele, temas são obscurecidos, 'invisibilizados', tornados pouco relevantes e sem direito de acesso ao espaço público. (SILVA, 2013). Nesse contexto, a força do pensamento crítico emerge como uma ferramenta fundamental no confronto com as posições pedagógicas que apreendem o currículo como um texto atravessado pela neutralidade política. A aparente naturalidade do 'desvio' é posta em xeque, permitindo a problematização de uma suposta 'ontologia do desviante'. O “desvio e o desviante" passam a ser vistos como construções sociais, como categorias contextuais e sempre situadas histórica e culturalmente, e não um dado pronto e bruto, extraído da natureza.

Tendo em mente esse quadro e a centralidade do/a professor/a no processo de construção de uma escola para todos/as - o que obrigatoriamente nos remete à elaboração do currículo -, consideramos de grande importância a criação de cursos de formação continuada para os/as profissionais do ensino, daqueles/as que estão diretamente ligados/as às realidades presentes em sala de aula, agentes morais capazes de fomentar uma prática educativa libertária, centrada na vida e numa "vida cheia de pensamento" ou, pelo contrário, agentes morais, comprometidos com a manutenção da ordem vigente. $\mathrm{O}$ fazer pedagógico, para além de um conjunto de procedimentos burocráticos, deve, nesse sentido, ser apreendido como uma atividade de autocrítica permanente por parte do/a professor/a, que deve pensar e repensar continuamente a sua vivência e a sua prática de ensino. A elaboração e oferta de um curso de cidadania e educação inclusiva encontram-se afinadas com esse ideal de uma prática que é permanentemente revisitada por seus atores/fazedores que, reconhecendo as dimensões políticas e éticas de seu trabalho, assumem a posição de defesa daqueles/as que ao longo da história foram impedidos de adentrar o espaço da sala de aula por não estarem enquadrados dentro da 'norma' - os ditos "anormais".

Referência à centralidade do 'pensamento', tal como apresentado por Hannah Arendt em seu texto Eichmann em Jerusalém: um relato sobre a banalidade do mal [2000]-como 'antídoto' para o mal. 
Cidadania e inclusão: desafios para a formação docente

\section{TRAJETÓRIA METODOLÓGICA}

O curso de Cidadania e Educação Inclusiva foi ministrado entre os meses de fevereiro e junho de 2015 e organizado em oito módulos de vinte horas cada. De um total de 25 pessoas matriculadas, 15 conseguiram realizar todas as atividades apresentadas até o final do curso. $\mathrm{O}$ grupo era formado por professores/as oriundos/as da rede pública de ensino. Toda a proposta visava proporcionar um espaço de sensibilização dos/as participantes, mediante trocas de experiências e apresentação de situações vividas no cotidiano de trabalho e que fossem consideradas paradigmáticas em sua trajetória profissional e acadêmica no trato com as pessoas portadoras de alguma singularidade mais evidente em sala de aula.

Um dos conceitos centrais que deram sustentação ao curso foi a concepção de 'exercício do pensamento', aqui definido a partir do referencial teórico de Hannah Arendt, que trata o pensamento como uma das atividades do 'espírito', distinta do mero acúmulo de informações e conhecimentos. Distinguir 'pensamento' de 'conhecimento' foi, de início, posto como um ponto central para que as pessoas participantes pudessem refletir sobre o formato e as intenções de suas práticas pedagógicas. Como se configura a sua docência? Que elementos éticos e políticos sustentam o seu fazer em sala de aula? A primazia é dada ao conbecer ou ao pensamento? Essas questões entraram em cena ao longo de diversos momentos de reflexão e troca de experiência entre os/as participantes no decorrer do curso.

Em linhas gerais e a título de esclarecimento, podemos afirmar de forma bem simplória que o conhecer implica em se elaborar teorias e resolver questões ou problemas de ordem técnica, ao passo que o pensamento nos remete a uma dimensão mais elaborada e sofisticada do 'espírito', sendo definido como um diálogo contínuo e profundo com nós mesmos; uma reflexão crítica sobre as nossas próprias ações, com ênfase na empatia e na resolução de conflitos morais fora dos enquadramentos dogmáticos que impedem o alargamento do pensar. (ARENDT, 2000; ARENDT, 2004).

Assim, o conceito de pensamento, tal como colocado por Hannah Arendt, nos remete a um terreno ético e político, aqui considerado fundamental para as práticas pedagógicas que ambicionam se colocar para além dos meros cumprimentos de procedimentos burocráticos e dos sistemas de avaliação de desempenho dos/as estudantes em sala de aula. O exercício do pensamento torna-se necessário para as ações que visam resgatar a dignidade dos "grupos difamados", tais como ciganos, negros, 'deficientes físicos e intelectuais', lésbicas, gays, transgêneros etc; corpos e subjetividades lançados no campo da abjeção e, portanto, espoliados em seus direitos, em suas dignidades e em suas vidas. 
Cidadania e inclusão: desafios para a formação docente

As aulas foram ministradas por professores/as de formações diversas - psicóloga, sociólogo, advogado, designer, cientista da computação, pedagoga e professor de Língua Brasileira de Sinais [libras]. Os módulos foram os seguintes: 'Cidadania e espaço escolar', 'Antropologia e inclusão', 'Fundamentos jurídicos da educação inclusiva', Fundamentos psicológicos da educação inclusiva', 'Tecnologias em sala de aula', 'Teorias do currículo', 'Fundamentos filosóficos da educação inclusiva' e 'Metodologia de projetos'. Além dos módulos foram oferecidas duas oficinas: uma de Libras e outra de Scratch Day.

Os encontros eram realizados uma vez por semana, sempre nas segundas-feiras e os/as professores/as que ministravam as aulas tinham a liberdade de - juntos com a turma - definir estratégias e modalidades de ensino-aprendizagem mais afeitas às suas propostas de trabalho. Fazendo um levantamento das técnicas acionadas no decurso das ações empreendidas na proposta em discussão, destacamos: análise de casos, relatos e compartilhamentos de situações vivenciadas, verificação dos conteúdos e alargamento dos conceitos que fundamentavam o curso, análise de vídeos curtos, atividades em pequenos grupos, análise de ambientes inclusivos e não inclusivos, troca de experiências com profissionais de outros campi e que trabalhavam especificamente com estudantes com necessidades específicas, leitura e discussão do projeto pedagógico de uma escola municipal, com o fim de apontar ou não nesse documento a exposição de estratégias inclusivas etc. Além das duas oficinas realizadas, contamos com a participação do coral de Libras do Instituto Federal do Espírito Santo/campus Itapina-ES. Ao final do curso, os/as participantes deveriam apresentar um ensaio crítico-reflexivo, conectando as suas experiências vividas em sala de aula com o arcabouço teórico e metodológico que ensejou o curso de Cidadania e Educação inclusiva.

Cabe ressaltar que considerando a dinâmica da sala de aula, as falas dos/as participantes não foram gravadas, mas marcadas e registradas num bloco de notas por parte de um dos professores do grupo de docentes que ministraram os módulos.

\section{RESULTADOS E ANÁLISES}

A realização do curso de Cidadania e Educação Inclusiva se configurou num importante momento de aprendizagem e troca de experiências entre professores/as participantes e ministrantes. Os encontros se apresentavam como um esforço de articulação entre as discussões teóricas e as vivências dos/as professores/as, de maneira que estes/as pudessem ver nas teorias desenvolvidas na academia, importantes ferramentas capazes de ampliar a sua percepção sobre o 
Cidadania e inclusão: desafios para a formação docente

tema da inclusão e intervir em suas realidades. Para além de um mero conjunto de conceitos, nosso desafio era exatamente o de pensar de que forma todas as categorias conceituais poderiam atuar no sentido de desconstruir posições arraigadas e valores já sedimentados e que, de certa forma, emperravam a inclusão de alguns grupos humanos no espaço da escola. Em rodas de conversa ficou evidenciado que no terreno da retórica, todos/as apresentavam posições favoráveis às políticas inclusivas. Todavia, colocados em confronto com situações reais, o desconforto em lidar com temas como a diversidade sexual na escola emergiu de forma considerável. Ou seja, quando se passava da retórica para o tratamento de questões mais pontuais e concretas, pensando em determinados grupos humanos com maiores dificuldades de inserção na escola, havia uma dificuldade maior de assimilar os sentidos da inclusão. Percebemos que a inclusão é um desafio de grande monta, quando pensada em suas dimensões multiculturais e críticas e que ela não se limita apenas aos grupos portadores de necessidades específicas, como é o caso mais evidente das pessoas com deficiências. Articulada com a cidadania e com o direito à educação, a complexidade da inclusão fica ainda mais acentuada. Provavelmente um dos grandes ganhos que tivemos com as atividades realizadas foi justamente o de termos tido a chance de ampliar o conceito de inclusão, mostrando que esta não se esgota nos domínios das deficiências físicas e intelectuais. Para tanto, foi fundamental que nos apropriássemos do conceito de 'educação inclusiva multicultural'. (XAVIER; CANEN, 2008).

O confronto com situações mais problemáticas foi feito mediante a realização de análise de casos nos quais diferentes marcadores sociais de diferença se cruzavam ou eram encontrados numa única pessoa, revelando a todos/as os/as presentes, as dificuldades de se trabalhar com categorias engessadas - próprias do senso comum - e que empobrecem a complexidade que corta a vida humana.

O consenso quanto a quem incluir girou em torno das pessoas com deficiências físicas, mas, mesmo assim, diversos/as participantes relataram situações vivenciadas, nas quais afirmaram conhecer colegas professores/as que são contrários à inclusão de cegos, surdos, 'cadeirantes' ou pessoas com deficiências intelectuais e isso por uma série de razões que vão desde o medo, o receio, as dificuldades de se trabalhar com esse público, até a repulsa e a abjeção sentidas por esses corpos disformes ou fora da norma.

Observamos que uma coisa é falarmos de deficiência física. Outra bem distinta é pensarmos em condições que são classificadas socialmente como moralmente inadequadas ou abomináveis. É o caso, por exemplo, das pessoas 'transgênero', cujas presenças quase não notamos nos espaços de nossas escolas. Perguntados sobre o que achavam da ausência de transgêneros nas escolas, as opiniões foram as mais diversas. Boa parte dos/as participantes 
Cidadania e inclusão: desafios para a formação docente

consideravam - por razões certamente éticas - inaceitável a ausência de tais categorias humanas nos bancos das salas de aula. No entanto, percebem tais indivíduos como dissonantes no contexto da escola. Muito provavelmente essa dissonância seja resultado na discordância que há entre essas subjetividades e as normas de gênero que regem as sociabilidades em nossa sociedade em geral e nas nossas escolas em particular. As escolas continuam sendo espaço para o igual, para 'o mais do mesmo', o que pode ser perceptível pela dificuldade com que lidamos com os 'fora da norma' - sujeitos tidos como agressores propositais das normas sociais e das nossas percepções 'pessoais' de mundo.

Nesse contexto, os/as professores/as participantes foram convidados a pensar sobre o que entendiam ou de que forma compreendiam a ideia de 'norma'. A operacionalização de um curso de inclusão deve primar pelo enfrentamento e pelo tratamento dessa questão. Sem uma avaliação cuidadosa sobre 'a norma', consideramos que parte das atividades de sensibilização e de questionamento dos próprios valores fica defasada. Frente a isso, ficou acordado que 'compreender' não significa necessariamente 'aceitar', mas fazer um movimento no sentido de se pensar a partir das categorias e das experiências de vida desse outro diverso e muitas vezes considerado 'abjeto' ou 'inferior'. Compreender nos leva a encarar a realidade com todas as implicações e desafios que esse olhar nos impõe. Autores como Hannah Arendt (2004), Michel Foucault (2000; 2010) e Judith Butler (2003) mostraram-se estratégicos em momentos de reflexão como esse.

Os contatos e o intercâmbio de experiências entre os/as participantes revelaram a presença de uma angústia em obter respostas prontas e diretas acerca dos dilemas e das questões que surgem em sala de aula. Isso cria um cenário no qual o/a professor/a que trabalha com crianças e adolescentes com algum tipo de deficiência, surge como uma personagem que desempenha seu papel quase que na condição de um monólogo em sala de aula, sem contar com o amparo de instituições sociais no momento de tomada de decisões ou de formatação de uma estratégia que melhor se enquadre com essa ou aquela necessidade de atenção e aprendizagem. Eis uma indagação surgida e que nos revela a dramaticidade do que aqui relatamos: "Como lidar com um adolescente portador da deficiência X e que tem uma sexualidade aflorada em sala de aula? Ele mexe com todo mundo e toca nas pessoas de forma invasiva. Como lidar com essa situação?”

Questões dessa ordem nos fizeram notar que há a realização de uma jornada solitária pelo/a professor/a que efetivamente assumiu o compromisso com a inclusão em sua sala de aula ou no campo de ação que se encontra sob sua influência. Cursos, formações, trocas de ideias, leituras etc, são, muitas vezes, empreitadas realizadas pelos/a próprios professores/as na solidão 
Cidadania e inclusão: desafios para a formação docente

de suas tarefas. Tivemos a oportunidade de ouvir relatos de estratégias idealizadas e acionadas por educadores/as sem qualquer tipo de suporte por parte das instituições responsáveis pela elaboração de políticas inclusivas. Consideramos essa uma questão central para uma reflexão mais elaborada e para uma maior sensibilização por parte dos agentes encarregados da gestão da educação em diversos lugares do Brasil. É óbvio que a formação dada a esses/as educadores/as deve contemplar os desafios que emergem da concretude das relações que se estabelecem na comunidade escolar; relações que trazem em seu bojo muitos ganhos, aprendizados e grandes alegrias, mas que certamente, também tem sido motivo de tristezas, decepções, frustrações e sofrimentos para professores/as e estudantes, que por vezes acumulam um histórico de fracassos escolares, em decorrência da falta de habilidade institucional em lidar com o que é diverso.

Uma das questões mais prementes diz respeito à necessidade de empreendermos ações que visem à formação de uma escola atravessada pela empatia. Não há como construirmos uma escola para todos/as sem a promoção nos espaços da comunidade escolar de uma cultura que valorize a empatia e a formação para a sensibilidade. A empatia apareceu diversas vezes como o afeto positivo capaz de pavimentar todo o percurso de elaboração e implementação das ações de inclusão - em suas diversas facetas - em sala de aula. A empatia aparece nesse cenário como o afeto que nos permite reconhecer o valor da diversidade e a humanidade do diverso ou do diferente que conosco divide os corredores, as salas de aula, enfim, todas as dependências da escola. Nesse cenário, pensando em casos específicos, a dilatação do currículo com vistas à realização de adaptações e acolhimento aos/às estudantes com deficiências intelectuais foi um dos pontos mais debatidos e valorizados, mas a operacionalização foi considerada mais complexa, exigindo o concurso de vários sujeitos sociais no processo de adaptações e ajustes das matrizes curriculares. Aqui, a troca de experiências com um grupo de professores/as de um outro campus do Instituto Federal do Espírito Santo, e que trabalha com inclusão revelou-se de grande valia para o andamento do curso. Pudemos contar com a participação de colegas de outro campus em alguns instantes de nosso percurso de formação. Seja no evento de abertura do curso, seja no oferta de oficinas de libras, seja nos relatos de experiências de profissionais mais versados na lida com as deficiências e as inclusões, os testemunhos de outros/as profissionais acerca do modo como enfrentaram e enfrentam cotidianamente os desafios colocados por essas questões, foi, certamente, um dos pontos altos do curso.

Tais ajustes ou a criação de ambientes de acolhimento para a pluralidade que habita a escola são recheados de questionamentos e de tomadas de posições de fundo ético e político. Isso porque impedir uma pessoa de frequentar ou de fazer parte do ambiente escolar, configura-se como uma forma de violência e violação de um direito humano básico, a saber, o direito de ter 
Cidadania e inclusão: desafios para a formação docente

acesso, de conhecer e de compartilhar o patrimônio cultural de sua comunidade, de sua sociedade, de seu grupo social. Dessa forma, ampliam-se as fronteiras daquilo que convencionalmente se denomina educação inclusiva, na medida em que passamos a cobrir um leque maior de corpos e de formas de existir nem sempre considerados no momento em que se fala em inclusão.

\section{CONSIDERAÇÕES FINAIS}

As discussões em torno da inclusão na escola abarcam uma série de dimensões que exigem, para tanto, a articulação de movimentos sociais e dos poderes públicos, bem como da comunidade escolar. Se por um lado, discute-se os aspectos jurídicos e éticos que legitimam o 'resgate' de uma dívida histórica com grupos estigmatizados, por outro, identificamos a persistência de ações de grupos sociais, no sentido de impedir que determinados segmentos da sociedade ascendam à cena pública em igualdade de direitos com o restante da população. Num movimento de vai e vem, de ganhos e de perdas, de avanços e recuos, os direitos das pessoas com deficiências, mas sobretudo das pessoas que integram comunidades afetivas distintas, passam a ser objetos de disputas e barganhas políticas. Nesse contexto, o/a professor apresenta as ambiguidades próprias da condição humana, ora atuando como promotor/a de mudanças e alianças em favor da inclusão, ora como reforço das posturas e dos valores que historicamente têm garantindo os lugares de desigualdade e de inferioridade social.

Tal movimento pendular pode ocorrer em função de valores conservadores bastante arraigados e que servem de norteadores da conduta e dos processos de tomada de decisão dessas personagens sociais. Concluímos que, com base nas indagações e nos embates ocorridos ao longo do curso, há uma dificuldade para se pensar a inclusão em suas variadas dimensões, uma vez que essa palavra parece ter se consolidado no imaginário dos indivíduos participantes, apenas em sintonia com os grupos portadores de deficiências. Talvez essa seja uma das questões a serem enfrentadas com mais profundidade nas futuras versões das atividades de extensão ofertadas no terreno da formação dos/as profissionais do ensino, sobretudo, quando reconhecemos que, a despeito dos desgastes lançados sobre a autoridade docente, o/a professor/a ainda se coloca como uma significativa referência moral e de formação de opinião, sendo, portanto, central em todas as propostas de políticas inclusivas, assentadas sobre valores como empatia, cidadania, diversidade e respeito pela alteridade. 
Cidadania e inclusão: desafios para a formação docente

\section{REFERÊNCIAS}

ARENDT, Hannah. Eichmann em Jerusalém: um relato sobre a banalidade do mal. São Paulo:Companhia das Letras, 2000.

ARENDT, Hannah. Responsabilidade e julgamento. São Paulo:Companhia das Letras, 2004.

ARENDT, Hannah. A condição Humana. Rio de Janeiro:Forense Universitária, 2010.

BUTLER, Judith. Problemas de gênero: feminismo e subversão da identidade. Rio de Janeiro:Civilização Brasileira, 2003.

CARRARA, Sérgio et al. Gênero e diversidade na escola: trajetórias e repercussões de uma política pública inovadora. Rio de Janeiro:Cepesc, 2011.

FOUCAULT, Michel. Microfísica do poder. Rio de Janeiro:Graal, 2000.

FOUCAULT, Michel. Os anormais. São Paulo: Martins Fontes, 2010.

SILVA, Tomaz Tadeu da Silva. Documentos de identidade: uma introdução às teorias do currículo. Belo Horizonte:Editora Autêntica, 2013.

XAVIER, Giseli Perelide Moura; CANEN, Ana. Multiculturalismo e educação inclusiva: contribuições da universidade para a formação continuada de professores de escolas públicas no Rio de Janeiro. Pro-Posições, Campinas, v. 19, n. 3, p. 225-242, Dec. 2008. 